\title{
Социальные сети как дополнительное средство обучения и формирования экологического сознания
}

\author{
Т. Д. Захарова ${ }^{1}$, Е. Ю. Иванова ${ }^{1}$, А. М. Луговской ${ }^{2}$ \\ ${ }^{1}$ Московский государственный областной университет, Российская Федерация \\ (141014, Московская область, г. Мытищи, ул. В. Волошиной, 24) \\ ${ }^{2}$ Московский государственный университет геодезии и картографии, Российская Федераиия \\ (105064, г. Москва, Гороховский пер., 4)
}

\begin{abstract}
Аннотация: Цель исследования - подтверждение гипотезы о возможности эффективного использования социальных сетей в экологическом и географическом образовании.

Meтоды. В России есть несколько наиболее популярных сетей. Их возможности можно использовать для образовательных целей. Особую роль они могут играть при формировании экологического сознания. В работе были использованы две наиболее популярные социальные сети, где участники педагогического эксперимента проходили составленный авторами курс. Результаты эксперимента были сравнены и проанализированы. В начале педагогического эксперимента уровень знаний участников оценивался путём анкетирования, в конце было проведено тестирование.

Результаты. Разрабатывая тематические уроки или специальные курсы, можно воздействовать не только на школьников, но и на молодых людей от 18 до 34 лет, которые более внимательно относятся к экологическим проблемам. Результаты исследования показали, что социальная сеть «Instagram» обладает большим потенциалом для ведения образовательной деятельности, так как вовлеченность и интерес участников были выше.

Bblводы. Вовлеченность в образовательный процесс будет выше у тех людей, которые заинтересованы поднимаемой в курсе проблемой. Использование средств наглядности создаёт более конкретные представления об изучаемых вопросах, эти средства обучения удобнее использовать в социальной сети «Instagram».
\end{abstract}

Ключевые слова: социальные сети, интернет, образовательные цели, экологическая пропаганда, экологическая культура.

Для цитирования: Захарова Т.Д., Иванова Е.Ю., Луговской А.М. Социальные сети как дополнительное средство обучения и формирования экологического сознания // Вестник Воронежского государственного университета. Серия: География. Геоэкология, 2021, № 1, с. 69-73. DOI: https://doi.org/10.17308/geo.2021.1/3258

\section{ВВЕДЕНИЕ}

На конец июня 2020 года социальной сетью «ВКонтакте» пользовались в России более 73 млн человек, тогда как в «Instagram» только в мае 2020 года входили 59,4 млн человек. Популярность социальных сетей остро ставит вопрос о надежности использования их как инструмента получения образования. Важной проблемой является оценка перспективы использования социальных сетей как дополнительного средства обучения и пробужде- ния мотиваций к осознанному поведению, в частности, формированию экологического сознания.

Интернет можно использовать в образовательных целях, создавая тематические сообщества в популярных социальных сетях, тем самым развивая экологическое сознание и повышая уровень экологического мышления у пользователей. Целью нашего исследования было сравнение двух наиболее популярных социальных сетей и подтверждение гипотезы об эффективности обра-

(C) Захарова Т. Д., Иванова Е. Ю., Луговской А. М., 2021

Захарова Татьяна Дмитриевна, e-mail: taniazaharowa@yandex.ru

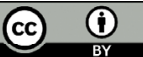
Контент доступен под лицензией Creative Commons Attribution 4.0 License. 
зовательной деятельности в них. Был составлен специальный курс и проанализирована вовлеченность аудитории от 18 до 34 лет в экологическую тематику. Такая возрастная категория была выбрана специально, так как пользователи социальных сетей этой возрастной категории соответствуют $67 \%$ пользователей российского интернета.

\section{МАТЕРИАЛЫ И МЕТОДЫ ИССЛЕДОВАНИЯ}

Социальные сети - перспективное средство, которое следует использовать в образовательных целях. С их помощью можно организовать учебную и внеучебную деятельность. Для реализации этой цели обычно используется личный аккаунт или отдельное сообщество. Для проведения нашего эксперимента использовался личный аккаунт в двух популярных сетях: «Instagram» и «Вконтакте». Одной из задач исследования было выявление наиболее удобной и актуальной платформы для ведения образовательной деятельности. Среднее количество участников в каждом аккаунте - 245 человек. Возраст аудитории варьировался от 18 до 34 лет. Образование участников исследования играло важную роль. $71 \%$ участников имели высшее образование или находились в стадии его получения. Студенты и выпускники экологи также приняли участие в исследовании. Их соотношение к общему количеству в аккаунте составило 38 \% от всех участников. Исследование проводилось на основе разработанного авторами курса «Устойчивое развитие и пути реализации», включающего наглядные и практические методы обучения. Курс был адаптирован для социальных сетей. Сначала были собраны констатирующие данные, анализ которых помог выявить уровень знаний участников по теме. Далее, на протяжении 4-х дней, проводился курс. Затем был проведён уточняющий эксперимент и проверена гипотеза исследования с помощью тестирования [2].

\section{ОБСУЖДЕНИЕ РЕЗУЛЬТАТОВ ИССЛЕДОВАНИЯ}

Используя такой метод обучения, мы должны понимать, что он не сможет глубоко раскрыть изучаемые темы, но поспособствует закрепить ранее усвоенный материал и сформировать необходимые навыки. Необходимо отметить, что для использования этого метода нужно заранее определить время коммуникации с пользователями, использовать правила построения коммуникации в сети, разработать план «занятий». Здесь могут использоваться следующие методы обучения: практический, наглядный и метод «дидактических игр». Подобная деятельность в социальных сетях должна мотивировать к самообразованию, повышать интерес к рассматриваемым темам [1].

Исследование было проведено в личном аккаунте, но рекомендуется создавать отдельные тематические сообщества [3], так как такие «страницы» будет легче найти. Размещать информацию рекомендуется на протяжении длительного периода времени или циклом курсов. В аккаунтах была рассмотрена тема авторского курса «Устойчивое развитие и пути реализации». Среднее количество участников в экспериментальных аккаунтах составило 245 человек на аккаунт, где 80 \% граждане от 18 до 34 лет.

Этапь эксперимента и сравнение полученных данных

День 1. 26.10.20. В двух аккаунтах социальных сетей были проведены одинаковые короткие дискуссии с использованием функции «историй», которые предусмотрены на этих интернет-платформах. Дискуссия была направлена на понимание глобальных мировых проблем и концепции «устойчивого развития», оценён уровень владения информацией у исследуемой аудитории. Средний охват «историй» в «Instagram» составил 90 человек. Оказалось, что 53 \% опрашиваемых знали о концепции «устойчивого развития», 47 \% слышали об этом в первый раз, a $76 \%$ участников не знали, что в России реализуется эта концепция. В «Вконтакте» истории просмотрело 20 человек, что на $72 \%$ ниже, чем в «Instagram». $100 \%$ опрашиваемых отметили, что слышали об «устойчивом развитии», $33 \%$ знали, что оно реализуется в РФ, а $67 \%$ посчитали, что не реализуется.

День 2. 27.10.20. Были проведены короткие дискуссии на тему «Глобальные проблемы мира и пути их решения» с возможностью выбрать варианты ответа и высказать краткое личное мнение. Дополнительно была размещена публикация с подробным объяснением концепции устойчивого развития и способов его реализации в мире. Охват «историй» в «Instagram» составил около 85 человек, а публикации - 143 человека. Респонденты высказали разные мнения о глобальных проблемах мира и их важности решения. 93 \% посчитали, что социальные проблемы влияют на качество окружающей среды и их необходимо решать наравне с другими проблемами. Охват «историй» «Вконтакте» составил около 19 человек, а публикации - 83 человека. Респонденты также высказали разные мнения о глобальных проблемах мира и их важности решения. 
День 3. 29.10.20. Он был посвящён проблеме «Бизнеса и устойчивого развития». Проведены краткие дискуссии о том, что агрессивные методы рекламы и продвижения товаров способствуют распространению концепции безграничного потребления, а также рассматривался вопрос о проблеме размещения развитыми странами промышленности в развивающихся странах, где есть пробелы в нормативно-правовой документации. В «Instagram» охват «историй» составил 85 человек, из них $82 \%$ знало об этих проблемах и поделилось своими взглядами на способы снижения перепотребления товаров. Охват «историй» в «Вконтакте» составил 20 человек, где $50 \%$ опрашиваемых знали об этой проблеме, и тоже предложили способы по решению этой проблемы.

День 4. 30.10.20. Подведение итогов. Был проведён тест, результаты которого отражали понимание и глубину знаний участников по концепции устойчивого развития. Вопросы предложенного теста составлены таким образом, чтобы респонденты могли самостоятельно найти на них ответ. Они частично дублировали поднятые темы. В «Instagram» респонденты справились с выполнением теста на $65 \%$, а в другой сети - на $70 \%$. Далее мы привели примеры задаваемых в тестировании вопросов.

1. Реализуется ли в России концепция устойчивого развития?

2. Влияют ли социальные проблемы на состояние окружающей среды? Почему?

3. Помогла ли Вам полученная информация из учебного курса задуматься об изменении своего образа жизни в более эколого-ориентированную сторону?

\section{ЗАКЛЮЧЕНИЕ}

Проанализировав полученные данные нами были сделаны следующие выводы. Несмотря на высокую популярность используемых для исследования сетей и на усреднённое одинаковое количество людей в них, в «Вконтакте» результаты по охвату были на $72 \%$ ниже. Не все 245 человек в аккаунтах участвовали в выполнении заданий, в «Instagram» проявили активность 37\%, а в «Вконтакте» всего 8 \%. Высокую степень вовлечённости показали студенты-экологи и выпускники экологических направлений образовательных учреждений. Следовательно, для образовательных целей нужно использовать «Instagram», так как у него более удобные инструменты для размещения информации.

Участникам тема «Устойчивое развитие» оказалась интересна и понятна. Они проявляли активное участие в дискуссиях и тестировании. Однако только $33 \%$ ответили, что полученная ими информация поможет изменить свою жизнь в более эколого-ориентированную сторону. После проведения эксперимента, участники были опрошены ещё раз и ответили, что им самим было удобнее использовать «Instagram», где информация воспринималась лучше.

Для того, чтобы образовательный процесс был более эффективным, рекомендуется простую информацию размещать в формате «историй» (не более 5 в день), глубокие и сложные вопросы раскрывать в публикациях. Дополнительно можно проводить «прямые эфиры» (длительностью до 1 часа) и отвечать на вопросы участников.

\section{СПИСОК ЛИТЕРАТУРЫ}

1. Бехтерева Л.Г., Марголис Н. Ю., Никитенко В.А. Возможности использования социальных сетей в современном образовательном процессе в вузах // Молодой ученый, 2015, № 6 (86), с. 575-578.

2. Коржуев А.В., Антонова Н.Н. Основы научно-педагогического исследования: учебное пособие для вузов. Москва: Изд-во Юрайт, 2020. 177 с.

3. Макова А. А., Есина М.Г. Уровень популярности социальных сетей «Социальные сети рядом» // Материалы IV Всероссийской научно-практической конференции с международным участием "Актуальные вопросы естествознания». Иваново, 2019, с. 353-358.

Конфликт интересов: Авторы декларируют отсутствие явных и потенциальных конфликтов интересов, связанных с публикацией настоящей статьи.

Поступила в редакциюю 16.11.2020

Принята к публикации 02.03.2021 


\title{
Social Network as an Additional Learning Tool and Formation of Ecological Consciousness
}

\author{
T. D. Zakharova ${ }^{1}$, E. Yu. Ivanova ${ }^{1}$, A. M. Lugovskoy ${ }^{2}$ \\ ${ }^{1}$ Moscow State Regional University, Russian Federation \\ (24, V. Voloshina St., Moscow Region, Mytishchi, 141014) \\ ${ }^{2}$ Moscow State University of Geodesy and Cartography, Russian Federation \\ (4, Gorokhovsky Lane, Moscow, 105064)
}

\begin{abstract}
Purpose. The purpose of the research is to confirm the hypothesis about the possibility of effective use of social networks in ecology and geography studies.

Methods. There are several most popular networks in Russia. Their capabilities can be used for educational purposes. They can play a special role in environmental awareness development. In the work, the two most popular social networks were used, where the participants of the pedagogical experiment took the course created by the authors. The experiment results were compared and analyzed. At the beginning of the pedagogical experiment, the level of the participants' knowledge was evaluated with the help of questionnaires, at the end, testing was carried out.

Results. By providing thematic lessons or special courses, it is possible to influence not only schoolchildren but also young people from 18 to 34 years old, who are more attentive to environmental problems. The results of the research showed that the social network "Instagram" has great potential for educational activities, as the involvement and interest of the participants were higher.

Conclusions. The involvement in the educational process will be higher for those people who are interested in the problem raised in the course. The use of visual aids provides a more clear notion of the issues being studied; these teaching aids are more convenient to use in the social network "Instagram".

Key words: social networks, Internet, educational purposes, environmental propaganda, environmental culture.

For citation: Zakharova T. D., Ivanova E. Yu., Lugovskoy A. M. Social Network as an Additional Learning Tool and Formation of Ecological Consciousness. Vestnik Voronezskogo gosudarstvennogo universiteta. Seria: Geografia. Geoekologia, 2021, no. 1, pp. 69-73. (In Russ.) DOI: https://doi.org/10.17308/geo.2021.1/3258
\end{abstract}

\section{REFERENCES}

1. Bekhtereva L. G., Margolis N.Yu., Nikitenko V.A. Vozmozhnosti ispol'zovaniya sotsial'nykh setey v sovremennom obrazovatel'nom protsesse $\mathrm{v}$ vuzakh [Possibilities of using social networks in the modern educational process in universities]. Molodoy uchenyy, 2015, no. 6 (86), pp. 575-578. (In Russ.)

2. Korzhuev A. V., Antonova N.N. Osnovy nauchno-pedagogicheskogo issledovaniya: uchebnoe posobie dlya vuzov [Fundamentals of scientific and pedagogical research: a textbook for universities]. Moscow: Izd-vo Yurayt, 2020. 177 p. (In Russ.)
3. Makova A.A., Esina M.G. Uroven' populyarnosti sotsial'nykh setey «Sotsial'nye seti ryadom» [The level of popularity of social networks "Social networks are nearby"]. Materialy IV Vserossiyskoy nauchno-prakticheskoy konferentsii s mezhdunarodnym uchastiem "Aktual'nye voprosy estestvoznaniya». Ivanovo, 2019, pp. 353-358. (In Russ.)

Conflict of interests: The authors declare no information of obvious and potential conflicts of interest related to the publication of this article.

Received 16.11.2020 Accepted 02.03.2021

(C) Zakharova T. D., Ivanova E. Yu., Lugovskoy A. M., 2021 $\varangle$ Tatiana D. Zakharova, e-mail: taniazaharowa@yandex.ru The content is available under Creative Commons Attribution 4.0 License. 
Захарова Татьяна Дмитриевна

магистр географо-экологического факультета Московского государственного областного университета, г. Мытищи, Российская Федерация, ORCID: 0000-00026443-0662, e-mail: taniazaharowa@yandex.ru

Иванова Елена Юрьевна

кандидат географических наук, доцент кафедры общей и региональной геоэкологии Московского государственного областного университета, г. Мытищи, Российская Федерация, ORCID: 0000-0001-7895-1533, e-mail: ivelena2010@mail.ru

Луговской Александр Михайлович доктор биологических наук, профессор, кандидат географических наук кафедры географии Московского государственного университета геодезии и картографии, г. Москва, Российская Федерация, ORCID: 0000-00023985-4535, e-mail: alug1961@yandex.ru
Tatiana D. Zakharova

Undergraduate of the Faculty of Geography and Ecology, Moscow State Regional University, Mytishchi, Russian Federation, ORCID: 0000-0002-6443-0662, e-mail: taniazaharowa@yandex.ru

Elena Yu. Ivanova

Cand. Sci. (Geogr.), Associate Professor of the Department of General and Regional Geoecology, Moscow State Regional University, Mytishchi, Russian Federation, ORCID: 0000-0001-7895-1533, e-mail: ivelena2010@mail.ru

Alexander M. Lugovskoy

Dr. Sci. (Biolog.), Professor of the Department of Geography, Moscow State University of Geodesy and Cartography, Moscow, Russian Federation, ORCID: 0000-00023985-4535, e-mail: alug1961@yandex.ru 